\title{
Multi-Winner Voting*
}

\section{MARC KILGOUR}

Wilfrid Laurier University, 75 University Avenue West, Waterloo, Ontario, N2L 3C5, Canada. E-mail: mkilgour@wlu.ca

\begin{abstract}
Multi-winner voting is a way to select a subset of candidates, rather than just one, in a single election process. It is easy to carry out, and has become common, but its properties are not well understood. Because the voter must use a single ballot to indicate his or her preferences over all of the candidates, many nuances of preference are difficult or impossible to express. Many forms of ballot have been proposed for multi-winner voting; for some of them, there are multiple ways to determine the winning subset from a set of submitted ballots. Generally, these counting procedures balance two objectives - to elect only candidates who are well-supported individually, and to elect a subset of candidates with broad support. The breadth of multi-winner ballots and counting procedures is surveyed, and some properties that are desirable in multi-winner voting are described.
\end{abstract}

Keywords: Social Choice, Elections, Computation.

\section{Votación con múltiples ganadores}

\section{RESUMEN}

La votación con múltiples ganadores es una forma de seleccionar un subconjunto de candidatos, en lugar de solo uno, en un solo proceso de elección. Es fácil de llevar a cabo y se ha vuelto de uso común, pero no se comprenden bien sus propiedades. Debido a que el votante debe usar una sola papeleta para indicar sus preferencias sobre todos los candidatos, muchos matices de preferencia son difíciles o imposibles de expresar. Se han propuesto muchas formas de votación para la votación de ganadores múltiples; para algunos de ellos, hay múltiples formas de determinar el subconjunto ganador de un conjunto de papeletas enviadas. En general, estos procedimientos de recuento equilibran dos objetivos: elegir candidatos que tengan un buen apoyo individual, y elegir un subconjunto de candidatos con amplio respaldo. Se estudia el alcance de los procedimientos de recuento y votación de ganadores múltiples y se describen algunas propiedades que son deseables en la votación con múltiples ganadores.

Palabras clave: Elección Social, Elecciones, Cálculo.

JEL Classification: C63, D71, D72, D81

\footnotetext{
* The author gratefully acknowledges the support of the Natural Sciences and Research Council of Canada under Grant No. 5023, and the 2017 Toulouse E-Democracy Summer School, supported by LABEX CIMI and GDR Policy Analytics.
}

Artículo recibido en octubre de 2017 y aceptado en noviembre de 2017

Artículo disponible en versión electrónica en la página www.revista-eea.net, ref. ə-36113 


\section{INTRODUCTION}

Many group decisions are made by voting, so the design of voting systems is an important problem of Political Economy. If the problem is to choose one of exactly two alternatives, the problem is easy; May's Theorem (1952) establishes that Majority Rule is the only voting system that is consistent with certain fundamental principles of democracy, and is as decisive as possible. But if the winner is to be chosen from more than two alternatives, May's Theorem does not apply. In fact, an enormous range of multi-candidate voting systems has been proposed, and there is no general agreement on which is best, or even on which systems are good. Brams and Fishburn (2002) and Laslier (2012) give details and recent developments in the controversy over electoral systems for single-winner elections.

The design of voting systems that produce multiple winners is an important variant of the single-winner problem. Procedures, though similar to procedures for single-winner elections, are of course more complicated. Yet multi-winner voting is carried out in a great range of contexts. An obvious example are the multi-winner elections that are used when citizens must choose a group of representatives. Multi-winner voting is also used by the marketing team of a retailer, when products to feature in advertising are selected, by the Program Committee of a conference, when it decides which contributed papers to accept, and by the Local Arrangements Committee of the conference, when it selects a set of menus for the conference banquet.

Yet multi-winner voting is increasingly common, in part because other subsetselection procedures are complex and time-consuming. Moreover, multi-winner ballots can be counted (i.e., the winning subset determined) using readilyavailable software; indeed, the entire procedure can be conducted on the internet. Nonetheless, multi-winner elections are only now coming under study - for a summary of recent theoretical results and new problems, see Faliszewski et al. (2017).

When a choice is to be made by multi-winner voting, there is a set of candidates, of which some are to be selected and others rejected, in a way that is determined by the input from the voters - that is, the ballots. Usually the number of candidates to be selected is fixed in advance. For most of this paper, we will assume that the election is to select $k>1$ of the candidates. Our objective is to summarize the possible ballots that have been proposed, as well as techniques for counting them (i.e. determining the winning subset of $k$ candidates).

Because we concentrate on ballots and counting, we will not be concerned with other important issues that are important in any election, such as identifying candidates, determining eligible voters and ensuring that they vote only once, maintaining ballot security, and verifying ballot counting. We will simply survey the possible ballots, describe various procedures for counting them, and 
suggest some desirable properties that those procedures might exhibit.

Any acceptable voting procedure must, in some sense, treat each voter the same, and give each candidate the same chance of winning. Besides these "fairness" considerations, other economic criteria apply. For example, a Paretoinspired condition is that when a winning set of candidates is compared with one that did not win, "most" voters should prefer the set that won. A "no-regret," or Nash equilibrium, criterion requires that no voter (or no small group of voters) be able to look at the election after the fact and conclude that voting differently would have produced a preferred outcome. Like single-winner elections, multiwinner elections ask voters to make choices, and concern the distribution of scarce resources (positions in the winning subset of candidates), so economic ideas should be applicable, and they are.

One justification for the existence of a variety of procedures is the fact that multi-winner voting may have a range of objectives. In general, the winning set of candidates should have two properties:

(1) Individual Support: Each candidate in the winning set should be wellsupported by the voters, in comparison to other candidates.

(2) Group Support: The winning subset, considered as a group, should be broadly-supported by the voters, in comparison to subsets that might have won but did not.

For example, most Program Committees place a high priority on selecting the best individual papers for the conference, and treat other considerations (such as the distribution of papers over subfields) as secondary. So if the Program Committee is voting on papers to include in the conference, it typically wants the winning subset to contain the papers that are recognized as strongest by the committee members, and regards diversity over subfields as less important. In other words, Individual Support is more important than Group Support.

In contrast, the best set of three menus for the conference banquet should be diverse. The ideal is that every conference attendee will find at least one menu acceptable. Thus the target should be a set of menus that maximizes the number of attendees who find at least one menu appealing, as opposed to a set comprised of menus each of which appeals to many attendees. In this case, Group Support is more important than Individual Support.

Usually, the two objectives of Individual Support and Group Support are roughly consistent, but often they are in partial conflict. A voting procedure that identifies the three best-supported choices may produce, say, three rather similar menus. The flaw here is called Tyranny of the Majority; a minority, which may be almost half, is unhappy. In general, different multi-winner voting procedures achieve a different balance between the objectives of Individual Support and Group Support. 
There are alternatives to a multi-winner vote for a group that wants to choose several alternatives out of many. The obvious one is to conduct a single-winner election in which the "candidates" are slates, or subsets, of alternatives that might be chosen. One advantage of this approach is that it gives voters the opportunity to express themselves on all possible winning sets; for example, voters may detect synergies, positive or negative, among candidates. Unfortunately, the slate approach is impractical in most cases due to a combinatorial explosion in the number of "candidates." If the numbers are small - for example if 2 candidates out of 4 are to be chosen - then there are 6 subsets to be compared - which is a reasonable task for most voters, so such an election is practical. But if the problem is to choose 3 candidates out of 8 , then each voter must assess 56 different slates, which is probably too much to ask. A multi-winner election is the only practical alternative.

To summarize issues in multi-winner voting, this article will begin with a brief review of voter preferences, and a discussion of the ways they may be expressed on the various available ballots. Then ballot-counting procedures will be discussed, illustrated with representative elections involving voters with fixed utilities for the candidates. Finally, some properties that have been proposed as criteria for good electoral procedures will be suggested, and ideas for future directions and emerging issues will be described.

\section{PREFERENCES AND BALLOTS}

When a voter fills out a ballot, the voter sends a message to the voting system about the voter's preferences. In a single-winner election with more than two candidates, a ballot always identifies the candidate favoured by the voter. Often, the ballot also gives the voter the opportunity to indicate something about his or her preferences over the other candidates, in case the first-choice candidate is not selected.

In multi-winner elections, there is even greater need for information about the voter's preferences over many candidates. Usually ballots offer the opportunity to support several candidates, and often to say something about preferences for other candidates, which might of course be relevant.

Nonetheless, there are some kinds of messages about candidate preferences that most ballots do not allow. Ballots typically refer only to individual candidates, even though the purpose of the election is to choose a subset containing more than one candidate. A consequence is that a voter cannot express some views that are pertinent to the selection of a set of winners, for example about candidate synergies - positive or negative.

To put it plainly, a fundamental problem of multi-winner voting is that ballots can describe only the voters' views of individual candidates, but nothing about how a group of candidates should be selected. Systems for multi-winner voting 
assume that each voter's preferences are, in some sense, additive, and that there are no synergies within any group of two or more candidates. The inability of voters to send messages about such nuances of preference is one reason why decisions by multi-winner voting should be avoided unless it is the only practical way to make the social choice.

In a multi-winner election, the particular subset of candidates selected is generally required to display adequate Group Support, which can be understood as a "diversity" requirement - many subgroups of the electorate are to be represented among the winners. There are two ways that a multi-winner voting system might encourage a suitable level of diversity. One is the imposition of Admissibility rules, which specify in advance the subsets of candidates that can win the election, defining them so as to achieve the required diversity. For example, within universities, it is common to find multi-winner elections in which the winning subset must include at least one member from each faculty, school, or department. The Conference Program Committee is implementing an Admissibility requirement if it decides in advance which subfields are to be represented in the papers selected for presentation at the conference. While Admissibility is in general effective, it has some problems, such as the issue of who is to decide the numbers of papers from each subfield, and perhaps even the specification of the subfields themselves, which may change over time.

The second strategy to improve the level of Group Support is to count the ballots in a way that raises the scores of subsets that are high in Group Support, relative to what they would be if only Individual Support mattered. Of course, subsets of candidates with high levels of Individual Support tend to do well in Group Support but, if most voters view the candidates similarly, there is room for a counting procedure that gives some weight to breadth, as opposed to amount, of support. Because Group Support and Individual Support are criteria that are sometimes in conflict, Multi-Winner Elections can be thought of as a kind of multi-criteria decision problem. Unfortunately, standard multi-criteria solutions are hard to apply.

To appreciate the range of ballot counting techniques, one must first understand the diversity of ballots. Figure 1 shows the ballots in common use for multi-winner elections. Note that all ballots are either Ordinal (indicating the voter's ranking of the candidates, or relative preferences) or Cardinal (indicating the voter's score for each candidate). Ordinal ballots rank the candidates, while Cardinal ballots give each candidate a grade or score. To make matters a little more complicated, approval ballots, where each candidate is approved or not, can be understood as both ordinal and cardinal.

Of course, there are many variants not indicated in Figure 1. Ordinal ballots may or may not permit ties, and are often truncated - the voter is asked to indicate only the top 3, or top 5, or top 10 candidates. Graded or range ballots 
require that each candidate receive a score, typically a number between 0 and 10 , or 0 and 100 . For an election in which $k$ candidates are to be selected, a cumulative ballot offers voters $k$ "votes," of which a candidate may receive more than one.

Figure 1

Ballots for Multi-Winner Elections

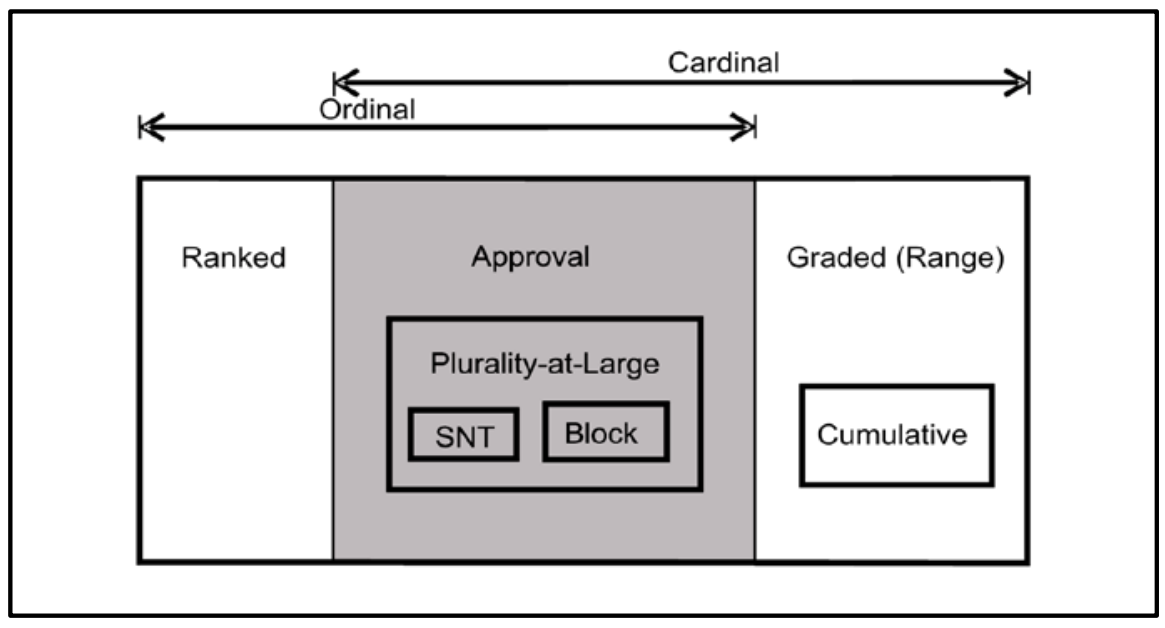

Source: Own elaboration.

Approval ballots are in a central position. Each voter either approves, or not, each candidate. Thus approval ballots may be considered to be ranked ballots in only two ranks are available, or graded ballots, in which the score of every candidate must be either 0 or 1 . The number of approvals that may be indicated on an approval ballot is, in general, unrestricted. However a plurality-at-large ballot permits a voter to approve at most $k$ candidates, where $k$ is the number of candidates to be elected; a Block ballot requires a voter to approve exactly $k$ candidates; and a Single Non-Transferable ballot requires each voter to approve one candidate (and is really a plurality ballot).

But the ability to express preferences on a ballot is only one issue. Other issues are how the voter should express his or her preferences on a particular ballot, and how the ballots are to be counted - that is, how the totality of ballots determines the subset of candidates that wins the multi-winner vote.

\section{COUNTING BALLOTS}

Of course, procedures for counting ballots - that is, for determining the winning subset - depend on the kind of ballots used. Moreover, even if the form of the ballots is fixed, there are many counting procedures. As noted above, 
many counting procedures are quite explicit in their attempt to trade off Individual Support for a candidate against Group Support for subsets including that candidate.

Table 1

Example Utilities

\begin{tabular}{|c|c|c|c|c|c|}
\hline & A & B & C & D & E \\
\hline Voter 1 & 4 & 5 & 10 & 9 & 2 \\
\hline Voter 2 & 5 & 2 & 9 & 7 & 1 \\
\hline Voter 3 & 3 & 4 & 1 & 5 & 6 \\
\hline Voter 4 & 9 & 0 & 10 & 7 & 8 \\
\hline Voter 5 & 7 & 6 & 1 & 5 & 2 \\
\hline Voter 6 & 0 & 2 & 1 & 3 & 10 \\
\hline
\end{tabular}

Source: Own elaboration.
To illustrate the procedures, we will apply them to an illustrative election that can be conducted using the different ballots and counted using various counting rules. We will begin with each voter's utilities for each candidate. In the example shown in Table 1 , a committee of $k=3$ candidates is to be elected in a multi-winner election. Note that there are $m=5$

candidates (A, B, C, D, and E), and $n=6$ voters.

We will assume that utilities for subsets of candidates are additive. We will also assume that each voter is sincere, and uses a "reasonable" strategy for filling out his or her ballot. We will deal with Approval Ballots separately from other Ordinal and other Cardinal.

\subsection{Ordinal Ballots}

The voters submit the ordinal

Table 2

Example: Ordinal Ballots

\begin{tabular}{|c|c|c|c|c|c|}
\hline & $\mathbf{1}^{\text {st }}$ & $\mathbf{2}^{\text {nd }}$ & $\mathbf{3}^{\text {rd }}$ & $\mathbf{4}^{\text {th }}$ & $5^{\text {th }}$ \\
\hline Voter 1 & C & D & B & A & E \\
\hline Voter 2 & C & D & A & B & E \\
\hline Voter 3 & E & D & B & A & C \\
\hline Voter 4 & C & A & E & D & B \\
\hline Voter 5 & A & B & D & E & C \\
\hline Voter 6 & E & D & B & C & A \\
\hline
\end{tabular}

Source: Own elaboration ballots shown Table 2 .

Single Transferable Vote (STV) always focuses on the number of firstchoices for each candidate. A crucial quantity is the Droop quota, $q$, the smallest integer $d$ such that more than $k$ candidates cannot receive at least $d$ first-choices each), that is, the greatest integer not greater than $q=m / k$; in this case, $q=2$. Any candidate who receives at least 2 votes in any round is elected. Both $\mathrm{C}$ and $\mathrm{E}$ are elected on Round 1, $\mathrm{C}$ with a surplus of 1 and $\mathrm{E}$ with a surplus of 0 . Any non-zero surplus must be "transferred"; the simplest way to do so is to downweight voters whose first choices achieve the surplus. Accordingly, voters 1, 2, and 4 are downweighted to 0.333 , and voters 3 and 6 are downweighted to 0 . In the second round, the scores for the remaining candidates are A: 1.333, B: 0, D: 0.666, so A wins. Thus the STV committee is ACE.

There are in fact many STV procedures. The process always continues until the requisite number of candidates is elected. In any round, if no candidate achieves quota in first choices, the candidate with the fewest first choices is 
dropped; that candidate's votes are then distributed to his or her second choices. But there are great differences in how surplus is transferred, how ties are treated, and how incomplete rankings are handled (Farrell, 2001).

An alternative procedure for Ordinal Ballots is to score the candidates by Borda Count (BOR). Candidate scores, summed over all voters, are $4(=m-1)$ for first place, 3 for second, 2 for third, and 1 for fourth. In the example, the Borda scores of the candidates are (in order) 11, 10, 13, 15, 11, so the Borda committee is ACD or CDE (tie).

\subsection{Cardinal Ballots}

The voters submit a cardinal score, within some specified range, for each candidate. We assume that the range is 0 to 10 , and use the candidate utilities in Table 1 as the range scores. The easiest way to count these ballots is Range Score (RNG), which means simply adding each candidate's scores, which for these ballots produces (in order) 28, 19, 32, 36, 29. It follows that the Range Score committee is CDE.

Reweighted Range Voting (RWR), a more sophisticated use of range ballots, assigns seats on the committee one at a time, downweighting each voter at each step, according to the total score the voter assigned to candidates who are already elected. Assume that range scores are in the interval $[0, M]$. If candidates $c_{1}, c_{2}, \ldots, c_{h}$ are elected in rounds $1,2, \ldots, h$, then the weight for voter $i$ in round $h+1$ is given by

$$
w_{i}^{h+1}=\frac{1}{1+\frac{1}{h M} \sum_{j=1}^{h} S_{i}\left(c_{j}\right)}
$$

where $s_{i}\left(c_{j}\right)$ is the score assigned by voter $i$ to the already-elected candidate $c_{j}$. The effect is to downweight differentially those voters who gave high scores to the candidates who are already elected. See Kok and Smith (2017) for more details.

For the example in Table 1, the Reweighted Range procedure elects D in the first round, then reweights the voters to $0.526,0.588,0.667,0.588,0.667$, and 0.769 , electing $E$ in the second round. In the third round, the new weights are $0.476,0.556,0.476,0.400,0,588$, and 0.435 , and $\mathrm{C}$ is elected. Thus the Reweighted Range committee is CDE.

\subsection{Approval Ballots}

As Figure 1 shows, Approval Ballots are both ordinal and cardinal, so in principle the procedures already covered apply to them. But most of these procedures do not work well on approval ballots, as typically they produce too many ties. However, many new procedures have been invented specifically for 
approval ballots. For details and original references, see Kilgour (2010) and Kilgour and Marshall (2012).

First, it is not obvious, given the utilities in Table 1, exactly which candidates a voter will approve. We assume that each voter casts an approval vote for every candidate with utility greater than that voter's average utility for all candidates. For example, Voter 1's average utility for the five candidates is 6.0 , so Voter 1 approves candidates $\mathrm{C}$ and $\mathrm{D}$, the only candidates whose

Table 3

Example: Approval Votes

\begin{tabular}{|c|c|c|c|c|c|}
\hline & A & B & C & D & E \\
\hline Voter 1 & & & X & X & \\
\hline Voter 2 & X & & X & X & \\
\hline Voter 3 & & X & & X & X \\
\hline Voter 4 & X & & X & X & X \\
\hline Voter 5 & X & X & & X & \\
\hline Voter 6 & & & & & X \\
\hline
\end{tabular}

Source: Own elaboration. utility (for Voter 1) exceeds 6.0. The approval votes following from this rule are shown in Table 3.

Note that with the approval votes of Table 3, the candidates' total approval vote counts are 3, 2, 3, 5, and 3 (in order). The Simple Approval (AV) procedure simply awards seats on the committee to the $k=3$ candidates with the highest approval vote counts, which means that the Simple Approval committee is a tie among ACD, ADE, and CDE.

Under the Satisfaction Approval (SAV) procedure, each voter's contribution to the score of a candidate that the voter approves is the inverse of the number of candidates approved by the voter. Thus Voter 6's support for Candidate E counts as 1, whereas Voter 4's support for candidates A, C, D, and E counts as $1 / 4$ each. Likewise, Voter 3 's approval is worth $1 / 3$ to Candidate E. Because 3, 4, and 6 are the only voters to support E, E's Satisfaction Approval score is $0+0+1 / 3+1 / 4+0+1=1.583$. The Satisfaction Approval scores of the five candidates, in order, are $0.917,0.667,1.083,1.75$, and 1.583 , and the Satisfaction Approval committee based on the approval votes of Table 3 is CDE.

Both Simple Approval and Satisfaction Approval are additive, meaning that the score of a subset of candidates is the sum of the scores of the individual candidates within it. Most scoring procedures do not share this property. For example, in the Modified Satisfaction Approval (MSA) procedure, a voter's contribution to the score of a subset is the number of approvals of that subset divided by the minimum of the size of the subset and the number of candidates approved by the voter. In our example of Tables 1 and 3, the Modified Satisfaction Approval committee remains CDE. Note how much candidate E benefited from the support of voter 6 , who approved no candidate other than E.

Another class of counting procedures for approval ballots are sequential in that committee positions are awarded one at a time, with voters reweighted at 
each step to reflect the number of candidates they supported who are already elected. In fact, the simplest version of this procedure, called Sequential Proportional Approval (SPA), is exactly Reweighted Range Voting in the context of approval ballots. Note that a voter's weight remains 1 until a candidate the voter approves is elected; after that, it drops to $1 / 2$; then, after two candidates are elected, it drops to $1 / 3$, etc.

For the example in Tables 1 and 3, candidate D, with 5 approval votes, is elected first. Then the voters are reweighted to (in order) $0.5,0.5,0.5,0.5,0.5$, and 1 . With these weights, Candidate $E$ is elected in the second round. Voter weights then become (in order) $0.5,0.5,0.333,0.333,0.5$, and 0.5 , and the next round results in a tie between candidates A and C. Thus ADE and CDE tie as the Sequential Proportional Approval committee.

The fractions used by the SPA procedure are exactly those of Jefferson (d'Hondt) apportionment, and SPA has been called Sequential Jefferson. This link suggests that sequential procedures can be linked to other apportionment methods. The Sequential Webster (SWB) procedure is based on Webster (Saint-Laguë) apportionment, using the weights 1, 1/3, 1/5, etc. As with apportionment, Webster tends to be produce a committee with greater Group Support (as opposed to Individual Support). But in the example of Tables 1 and 3 , the Sequential Webster committee is again a tie between ADE and CDE.

Generalized Approval procedures assign a score to each subset of size $k$; the score is the sum over all voters of a number that measures the degree to which the subset represents the voter, which depends on the number of candidates in the subset who were approved by the voter. The possible values of the measure called a rep sequence $r(0), r(1), r(2), \ldots$ where $r(0)=0, r(1)=1$, and $r(j) \geq r(j-1)$. Formally, voter $i$ 's contribution to the score of subset $S$ is $r\left(\left|V_{i} \cap S\right|\right)$, where $V_{i}$ is the set of candidates approved by voter $i$ and $|$.$| represents cardinality (size). Thus$ $\left|V_{i} \cap S\right|$ is the number of candidates in $S$ approved by voter $i$. Generalized Approval procedures are computationally demanding, as each possible winning subset must be scored separately.

One important group of Generalized Approval procedures are called Representation Procedures. For $r \geq 1$, the REP-r procedure is defined by the rep sequence containing $r$ zeros followed by ones. For example, the REP-1 procedure, also called Chamberlin-Courant, is based on the rep sequence $0,1,1$, $1, \ldots$, while the REP-2 procedure is based on $0,0,1,1,1, \ldots$. . For the approval votes in Table 3, the REP-1 committee is a tie of ACE, ADE, BCE, BDE, and $\mathrm{CDE}$, while the unique REP-2 committee is BCD.

The sequences that are the basis of the apportionment-related procedures can be interpreted as rep sequences, giving rise to Generalized Approval procedures. For example, the Proportional Approval (PA) Procedure, also called Simultaneous Jefferson, is based on the rep sequence $0,1,1+1 / 2,1+1 / 2+$ 
$1 / 3, \ldots$, while the Simultaneous Webster (WEB) procedure is based on the rep sequence $0,1,1+1 / 3,1+1 / 3+1 / 5, \ldots$. For the approval votes of Table 3 , ADE and CDE tie for Proportional Approval committee and also for Simultaneous Webster committee.

An entirely different class of procedures for multi-winner approval voting are called Centralization Procedures, and are based on distances between subsets. The Hamming distance between sets $V$ and $S$, denoted $D(V, S)$, equals the number of elements that are in one of $V$ and $S$, but not both. The Minisum (MMS) committee is the set of $k$ candidates, $S$, that minimizes the sum over all voters $i$ of $D\left(V_{i}, S\right)$, and the Minimax (MMX) committee is the set of $k$ candidates, $S$, that minimizes the maximum of $D\left(V_{i}, S\right)$ over all voters $i$. For the approval votes in Table 3, ACD, ADE and CDE are tied for Minisum committee, while the Minimax committee is uniquely ADE.

Centralization Procedures tend to be very sensitive to outliers; one proposed variation is to weight ballots in a way that is proportional to their frequency and inversely proportional to their distance from other ballots. The resulting procedures are called Weighted Minisum (WMS) and Weighted Minimax (WMX). For the six ballots in the example, the weights (multiplied by 100) are 8.33, 8.33, 8.33, 8.33, 7.14, and 6.25, respectively. The effect is substantial; the Weighted Minisum winner is ADE, while ABD, ADE, and BCD tie as the Weighted Minimax committee.

Other procedures are available, and a few have been skipped for brevity but are shown in Table 4, below. Table 4 acts as a summary; it establishes that the example in Table 1 can give rise to a wide variety of outcomes, and that ties are relatively frequent. (It has often been observed that ties are more common in elections, like the example, with relatively few voters and candidates). Nonetheless, it is remarkable that, of the 10 possible winning subsets, only two are not selected (at least as part of a tie) by any method.

As noted earlier, there are some multi-winner elections for which the number of winners is typically not specified in advance. Examples include elections for honorary status, and inclusion on a shortlist (as a step in assessing the applicants for a position). For such elections, the procedures described above are not directly applicable, as the voters must determine $k$, as well as the subset of size $k$. For procedures that work by scoring individual candidates (which includes BOR, RNG, AV, and SAV), a common solution is to specify some threshold score - every candidate whose score exceeds the threshold is elected. There are also procedures that determine a set of winners intrinsically - that is, directly from the ballots, without any imposed threshold. For details, see Kilgour (2016). 
Table 4

Summary of Results for Example of Table 1

\begin{tabular}{|c|c|c|c|c|c|c|c|c|c|c|c|}
\hline & No. & ABC & ABD & ABE & ACD & ACE & ADE & BCD & BCE & BDE & CDE \\
\hline STV & 1 & & & & & X & & & & & \\
\hline BOR & 2 & & & & $\mathrm{X}$ & & & & & & $\mathrm{X}$ \\
\hline RNG & 1 & & & & & & & & & & $\mathrm{X}$ \\
\hline RWR & 1 & & & & & & & & & & $\mathrm{X}$ \\
\hline CUM & 1 & & & & & & & & & & $\mathrm{X}$ \\
\hline AV & 3 & & & & $\mathrm{X}$ & & $\mathrm{X}$ & & & & $\mathrm{X}$ \\
\hline SAV & 1 & & & & & & & & & & $\mathrm{X}$ \\
\hline MSA & 1 & & & & & & & & & & $\mathrm{X}$ \\
\hline SPA & 2 & & & & & & $\mathrm{X}$ & & & & $\mathrm{X}$ \\
\hline SWB & 2 & & & & & & $\mathrm{X}$ & & & & $\mathrm{X}$ \\
\hline REP-1 & 5 & & & & & $\mathrm{X}$ & $\mathrm{X}$ & & $\mathrm{X}$ & $\mathrm{X}$ & $\mathrm{X}$ \\
\hline REP-2 & 1 & & & & & & & $\mathrm{X}$ & & & \\
\hline PA & 2 & & & & & & $\mathrm{X}$ & & & & $\mathrm{X}$ \\
\hline WEB & 2 & & & & & & $\mathrm{X}$ & & & & $\mathrm{X}$ \\
\hline MSM & 3 & & & & $\mathrm{X}$ & & $\mathrm{X}$ & & & & $\mathrm{X}$ \\
\hline MMX & 1 & & & & & & $\mathrm{X}$ & & & & \\
\hline WMS & 1 & & & & & & $\mathrm{X}$ & & & & \\
\hline WMX & 3 & & $\mathrm{X}$ & & & & $\mathrm{X}$ & $\mathrm{X}$ & & & \\
\hline BLO & 3 & & $\mathrm{X}$ & & & & & $\mathrm{X}$ & & $\mathrm{X}$ & \\
\hline PAL & 3 & & & & $\mathrm{X}$ & & $\mathrm{X}$ & & & & $\mathrm{X}$ \\
\hline SNT & 1 & & & & & $\mathrm{X}$ & & & & & \\
\hline
\end{tabular}

Source: Own elaboration.

\section{CONCLUSIONS}

Multi-winner voting is now a common procedure, often using approval ballots. Typical implementations are illustrated by the university or conference committee examples (selecting papers for presentation, or menus for a banquet), and others are informal. Some conference-management software also implements multiwinner voting. While many voting procedures have been proposed, the most common seems to be simple approval, and the tradeoff of Individual Support versus Group Support seems not to have received much attention.

Naturally, the question of which procedure to recommend in a particular election has arisen, but few convincing guidelines have been proposed. It is possible to formulate many properties of voting procedures, and to assess specific procedures to determine whether they exhibit the property. But if the experience of single-winner procedures is a guide, there will not likely be any general agreement on which multi-winner procedure best, or even on which systems are good, and in what circumstances.

Nonetheless, Faliszewski et al. (2017) makes a good start on determination of properties of multi-winner procedures (with fixed number of winners). Their work will no doubt stimulate additional research in both the design and 
assessment of multi-winner voting procedures. And the increasing popularity of multi-winner elections ensures that there will be opportunity to test conclusions against real-world experience.

\section{BIBLIOGRAPHY REFERENCES}

BRAMS, Steven J. and FISHBURN, Peter C. (2002). "Voting procedures" Chapter 4 of Handbook of Social Choice and Welfare (ed. Kenneth J. Arrow, Amartya Sen, and Kotaro Suzumura) Vol 1, Elsevier, pp. 173-226.

FARRELL, D. M. (2001). Electoral Systems: A Comparative Introduction. New York: Palgrave.

FALISZEWSK, Piotr; SKOWRON, Piotr; SLINKO, Arkadii and TALMON, Nimrod (2017). "Multiwinner Voting: A New Challenge for Social Choice Theory" Chapter 2 of Trends in Computational Social Choice (Ulli Endress, editor), Al Access, 27-47.

KILGOUR, D. Marc. (2010). "Approval Balloting for Multi-Winner Elections," Chapter 6 in Handbook on Approval Voting (ed. Jean-François LASLIER and M. Remzi SANVER) Springer, Heidelberg, pp. 105-124.

KILGOUR, D. Marc and MARSHALL, Erica (2012). "Approval Balloting for Fixed-Size Committees." Electoral Systems: Paradoxes, Assumptions, and Procedures (ed. Moshé Machover and Dan Felsenthal, Springer, Heidelberg, pp. 305-326.

KILGOUR, D. Marc. (2016). "Approval Elections with a Variable Number of Winners" Theory and Decision, 81, pp. 199-211.

KOK, Jan and SMITH, Warren D. (2017). "Reweighted Range Voting - a Proportional Representation voting method that feels like range voting, www.rangevoting.org/RRV. [Accessed 2017-11-10].

LASLIER, J. F. (2012). "And the loser is... plurality voting" Chapter 13 of Electoral Systems (ed. DS Felsenthal and M. Machover). Springer, Berlin, pp. 327-351.

MAY, Kenneth O. (1952). "A set of independent necessary and sufficient conditions for simple majority decisions." Econometrica 20, 4, pp. 680-684. JSTOR 1907651. 
